\title{
Researchers pay the cost of research
}

To the Editor - Wellcome, and the research we support, aims to be a social good. We are a politically and financially independent foundation, and in our mission to improve health by helping great ideas to thrive we have touched the lives of millions of people. However, this should not come at the expense of those who deliver that impact.

A career in research offers many fulfilling features, but it can also take a personal toll. The level of 'burn out' among academics is now comparable with 'high-risk' occupations such as healthcare professionals, with younger people particularly at risk ${ }^{1}$. Partly fuelled by the power dynamics within research teams, bullying and harassment is widespread and tolerated - surveys suggest that $25-35 \%$ of academics have been bullied in the workplace in the past year, compared to $10-14 \%$ of the general population ${ }^{2}$.

In a recent open consultation we shared via our network, $722 \mathrm{PhD}$ supervisors (45\%) said they had noticed increasing cases of mental health issues among $\mathrm{PhD}$ students ${ }^{3}$. Our data (Fig. 1) indicate that while most $\mathrm{PhD}$ students remain satisfied with their work-life balance, satisfaction levels appear to have been declining for many years.

This culture of research needs to change, and we want to be part of that change. While much of the evidence remains anecdotal or self-reported, it's clear that there are issues across the system that are putting researchers, the quality of research and the relationship between research and society at risk.

\section{Building a better research culture} The factors driving poor research culture are complex and connected. Existing initiatives such as Wellcome's new bullying and harassment policy have attempted to isolate and address single symptoms, while broader schemes such as the Royal Society's Changing Expectations programme are struggling to secure the scale of change needed $^{4,5}$. To generate real progress, Wellcome is committing to making research culture a priority for every part of our organization, and adopting the consistent approach needed to tackle the root causes of a poor research culture.

Our first target will be to improve management and leadership - a driver that was highlighted in our PhD survey data, and which is linked to many poor research practices. The current system predominantly rewards 'excellence' based on what a researcher produces, while under-emphasising how the research was

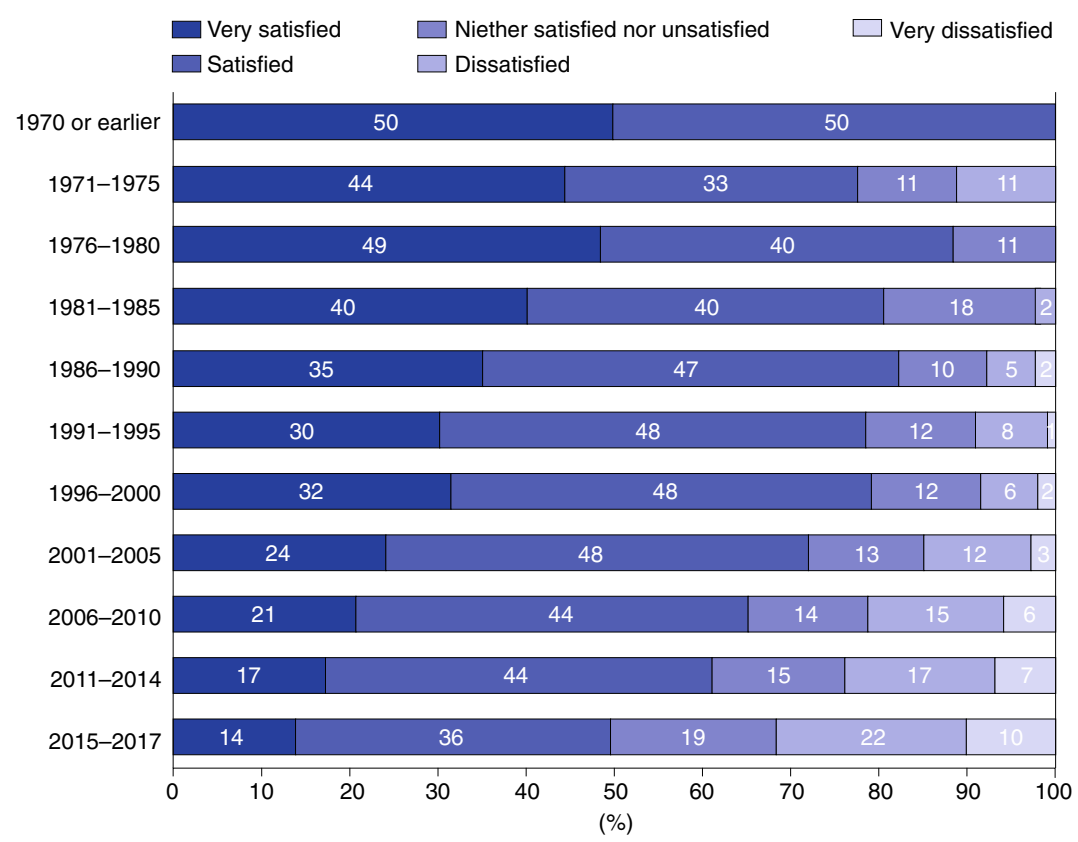

Fig. 1 | Work-life balance satisfaction. Response from a total of 1,434 individuals with PhDs to the question 'As a PhD student, how satisfied were you with your work-life balance?' Data are divided according to the year of PhD completion. Adapted from ref. ${ }^{3}$, Wellcome.

produced. Factors such as good management of a team should be supported, rewarded and required.

Achieving this will require changes across the system, including from individuals, institutions and funders like us. It may require us to reimagine the way Wellcome operates as a funder - from the support we provide to researchers, through to the way we assess grant applicants. Augmenting the definition of excellence in this way will not undermine the importance of ideas and outputs but put these in the context of a researcher's conduct.

Improving management and leadership will lay the foundations for a broader period of cultural change. This will help attract and retain a more diverse and inclusive research workforce, who would be able to thrive in a system that sees their well-being and mental health as an asset. It could help recognize a broader set of contributions to research and ensure the research endeavour operates within society's expectations.

\section{Working together to reimagine research} We believe the time to act is now. We want to open up the conversation with researchers, and those who support research, to make their voices heard. We want to hear where the challenges are, and how the research system could do better. These challenges are not unique to the UK and we want to learn from places around the world that have nurtured great working environments, both within academia and across other sectors.

We're committed to acting on these findings. This will be a long-term process, but Wellcome wants to play a leading role in making change happen. It's time that researchers didn't pay the price of an unsustainable system.

Ben Bleasdale

Wellcome Trust, London, UK.

e-mail:b.bleasdale@wellcome.ac.uk

Published online: 22 July 2019

https://doi.org/10.1038/s41563-019-0443-z

References

1. Watts, J. \& Robertson, N. Educ. Res. 53, 33-50 (2010).

2. Keashly, L. When Debate, Discourse, and Exchange Go Bad: Bullying in the Academic Workplace (National Communication Society, 2015); http://comm.wayne.edu/files/keashly_spectra2015.pdf

3. Coriat, A.-M., Chen, C.-M., Thakur, M., Phillips, G. \& Lloyd, S. Figshare https://doi.org/10.6084/m9.figshare.7309163.v2 (2018).

4. Bullying and harassment policy. Wellcome https://wellcome.ac.uk/ funding/guidance/bullying-and-harassment-policy (2019).

5. Research culture. Royal Society https://royalsociety.org/topicspolicy/projects/research-culture/ (2019). 